\title{
Erratum to: Dynamic hysteresis control of lift on a pitching wing
}

David R. Williams ${ }^{1} \cdot$ Xuanhong An $^{1} \cdot$ Simeon Iliev $^{1} \cdot$ Rudibert King $^{2}$. Florian Reißner ${ }^{2}$

Published online: 17 July 2015

(C) Springer-Verlag Berlin Heidelberg 2015

\section{Erratum to: Exp Fluids (2015) 56:112 \\ DOI 10.1007/s00348-015-1982-y}

In the original publication of the article, a term is missing in Eq. 5. The correct version of Eq. 5 is

$\tau_{1} \frac{d X}{d t}+X=X_{0}\left(\alpha_{s}\right)+X_{0}^{\prime}\left(\alpha_{s}\right) \cdot\left(u-\tau_{2} \dot{u}\right)$

This article belongs to a Topical Collection of articles entitled Extreme Flow Workshop 2014. Guest editors: I. Marusic and B. J. McKeon.

The online version of the original article can be found under doi:10.1007/s00348-015-1982-y.

David R. Williams

williamsd@iit.edu

1 MMAE Department, Illinois Institute of Technology,

Chicago, IL 60616, USA

2 Faculty of Process Sciences, TU Berlin, 10623, Berlin, Germany 